Fetal Diagnosis and Therapy

\title{
Diagnosis of Severe Fetomaternal Hemorrhage with Fetal Cerebral Doppler: Case Series and Systematic Review
}

\author{
Federica Bellussi Antonella Perolo Tullio Ghi Aly Youssef Gianluigi Pilu \\ Giuliana Simonazzi \\ Department of Medical and Surgical Sciences, Alma Mater Studiorum University of Bologna, Bologna, Italy
}

\author{
Key Words \\ Doppler ultrasound - Doppler velocimetry · Fetal anemia . \\ Fetal diagnosis · Fetal monitoring · Fetomaternal \\ hemorrhage $\cdot$ Intrauterine transfusion - Perinatal outcome \\ Prenatal counselling · Middle cerebral artery Doppler
}

\begin{abstract}
Objectives: To analyze the role of middle cerebral artery (MCA) peak systolic velocity (PSV) in the prediction of severe fetomaternal hemorrhage $(\mathrm{FMH})$ and to compare it with standard biophysical assessment. Data Sources: Retrospective review of cases of FMH seen in our unit and systematic review of the literature. Results: We followed the MOOSE guidelines to review the literature. From 838 articles, 16 were selected. In total, 35 women, including 3 cases from our center and 32 obtained from the literature search were included. Diagnosis of FMH was always confirmed by laboratory tests. Patients were seen at $31 \pm 5$ weeks' gestation (range 16-39) and the most frequent indication for referral was decreased perception of fetal movements. Cardiotocography (CTG) upon admission was sinusoidal in 18 cases, nonreactive in 6, decelerative in 2 and tachycardic in one. MCA-PSV was abnormal in all cases but one. There were 2 perinatal deaths. The mean hemoglobin concentration at birth or at intrauterine transfusion was $4.8 \pm 1.9 \mathrm{~g} / \mathrm{dl}$. Discussion: The most accurate predictor of FMH was fetal MCA-PSV. CTG was always
\end{abstract}

abnormal but the pattern was frequently nonspecific. We suggest including fetal cerebral Doppler in the evaluation of patients with decreased fetal movements, particularly in those cases with ambiguous results of biophysical testing.

(c) 2016 S. Karger AG, Basel

\section{Objectives}

Fetomaternal hemorrhage (FMH) is a well-established cause of fetal anemia. The reported incidence is variable depending on the method of ascertainment and the threshold employed and ranging from 0.3 to 1 in 1,000 births [1-4]. The consequences of FMH encompass a wide spectrum of severity from neonatal anemia to intrauterine demise. Severe FMH is a life-threatening complication and has been estimated to cause up to $14 \%$ of fetal deaths $[5,6]$.

Prenatal diagnosis of severe FMH is difficult. A decreased perception of fetal movements [7-12] and abnormal cardiotocography (CTG) $[3,10]$ are usually present. More recently, increased peak velocities in the middle cerebral arteries (MCA-PSV) detected by Doppler ultrasound have been described $[8,13-26]$. Our objective was to evaluate the role of MCA-PSV in the prediction of severe FMH and to compare it with standard methods of biophysical assessment in our own experience and in a systematic review of the available literature.

\section{KARGER}

(c) 2016 S. Karger AG, Basel

E-Mail karger@karger.com

www.karger.com/fdt
Federica Bellussi, MD

Department of Medical and Surgical Sciences

Alma Mater Studiorum University of Bologna

Via Massarenti 13, IT-40138 Bologna (Italy)

E-Mail federicakbh@yahoo.it 
Table 1. Clinical data of case series

\begin{tabular}{|c|c|c|c|c|c|c|c|c|c|}
\hline Case & $\begin{array}{l}\text { Indication } \\
\text { for referral }\end{array}$ & $\begin{array}{l}\text { Weeks' } \\
\text { gestation }\end{array}$ & $\begin{array}{l}\text { CTG } \\
\text { pattern }\end{array}$ & $\begin{array}{l}\text { MCA-PSV, } \\
\text { MoM }\end{array}$ & $\begin{array}{l}\text { Estimated } \\
\mathrm{Hb}, \mathrm{g} / \mathrm{dl}\end{array}$ & $\begin{array}{l}\text { Hb at } \\
\text { birth, g/dl }\end{array}$ & $\begin{array}{l}\text { Mode of } \\
\text { delivery }\end{array}$ & $\begin{array}{l}\text { Birth } \\
\text { weight, g }\end{array}$ & Clinical remarks \\
\hline 1 & $\begin{array}{l}\text { decreased fetal } \\
\text { movements }\end{array}$ & 35 & decelerative & 1.96 & 5.2 & 4 & $\begin{array}{l}\text { cesarean } \\
\text { section }\end{array}$ & 2,850 & $\begin{array}{l}\text { neonatal transfusion, respiratory } \\
\text { distress syndrome, discharged in } \\
\text { good condition }\end{array}$ \\
\hline 2 & $\begin{array}{l}\text { decreased fetal } \\
\text { movements }\end{array}$ & 32 & sinusoidal & 2.6 & 4.3 & 2.8 & $\begin{array}{l}\text { cesarean } \\
\text { section }\end{array}$ & 2,165 & $\begin{array}{l}\text { neonatal transfusion, respiratory } \\
\text { distress syndrome, discharged in } \\
\text { good condition }\end{array}$ \\
\hline 3 & $\begin{array}{l}\text { decreased fetal } \\
\text { movements }\end{array}$ & 37 & nonreactive & 1.86 & 6.3 & 5.7 & $\begin{array}{l}\text { cesarean } \\
\text { section }\end{array}$ & 3,000 & $\begin{array}{l}\text { neonatal transfusion, respiratory } \\
\text { distress syndrome, discharged in } \\
\text { good condition }\end{array}$ \\
\hline
\end{tabular}

\section{Data Sources}

FMH covers a wide span of severity. In our review, we considered severe those cases resulting in perinatal death, having severe neonatal anemia (hemoglobin concentration, $\mathrm{Hb} \leq 9 \mathrm{~g} / \mathrm{dl}$ ) or requiring prenatal or postnatal transfusions.

\section{Case Series}

We conducted a retrospective review of the medical records of all pregnant women who delivered at our University Hospital with a confirmed diagnosis of FMH from January 2011 to December 2014. We included all cases that had undergone assessment of fetal MCA-PSV, obtained as previously described [27]. FMH was always confirmed by flow cytometry. In all cases, a detailed followup were obtained.

\section{Systematic Review}

The systematic review was performed according to the Metaanalysis Of Observational Studies in Epidemiology (MOOSE) guidelines [28]. We systematically searched PubMed and ClinicalTrials.gov from April 1990 to June 2014 for the following terms: 'fetomaternal hemorrhage', 'fetomaternal hemorrhage and middle cerebral artery Doppler', 'fetal anemia and middle cerebral artery Doppler' and 'fetomaternal hemorrhage and ultrasound'.

We included all studies describing FMH resulting in fetal anemia evaluated antenatally with Doppler sonography MCA-PSV and confirmed by specific maternal tests (Kleihauer-Betke or flow cytometry test) from January 1990 to April 2014. The reference lists of the returned manuscripts were also evaluated. All of the identified articles were then limited to English language and human subjects. Duplicates were removed. Two independent authors (F.B. and G.S.) conducted the literature search. Identification of relevant studies was carried out through abstract screening. The full text of these articles was retrieved and studies which met inclusion criteria were selected. Inclusion criteria were: (1) English language; (2) documented MCA Doppler assessment; (3) laboratory confirmation of FMH. Disagreements about the decision to include a study were resolved by consensus, and in consultation with a third author (G.P.) if necessary. We investigated first the indication for referral, the CTG pattern and MCA-PSV value of all cases. When more than one sonographic assessment was performed, we collected data about the first one reported (the first MCA-PSV assessment and the subsequent hemoglobin concentration before intrauterine transfusion or at birth) $[8,10,13,14,16-22,24-26]$.
Secondly, we reviewed the antenatal and postnatal complications associated with this condition and the need for fetal or neonatal transfusions. We focused on the correlation between the fetal $\mathrm{Hb}$ calculated from the MCA-PSV and $\mathrm{Hb}$ at birth or at the time of intrauterine transfusion. Where not available, the estimated $\mathrm{Hb}$ value was retrieved from the MCA-PSV, as previously described [29]. When only hematocrit $(\mathrm{Ht})$ was reported, $\mathrm{Hb}$ was calculated using the standard threefold conversion $(\mathrm{Hb}=\mathrm{Ht} / 3)[30]$.

\section{Statistics}

Descriptive statistics are provided. Data are presented as mean \pm standard deviation (SD) unless otherwise specified.

\section{Results}

\section{Case Series}

A summary of clinical data of cases seen in our Unit is provided in table 1.

Case 1. A 38-year-old primigravida with an uncomplicated prenatal course was seen at 35 weeks and 3 days of gestation because of decreased fetal movements. The CTG was nonreactive with decelerations. Sonography revealed a fetus of normal size for gestation, with no movements, normal amniotic fluid volume and umbilical artery Doppler. MCA-PSV was $99 \mathrm{~cm} / \mathrm{s}$, or 1.9 multiples of the median (MoM) for gestational age (estimated $\mathrm{Hb}$ concentration $5.2 \mathrm{~g} / \mathrm{dl}$ ) [29]. A 2,850-gram female infant with Apgar score of 7 and 9 at 5 and 10 min was delivered by an emergency cesarean section. Hb was $4 \mathrm{~g} / \mathrm{dl}$ and flow cytometry confirmed the presence of a severe FMH. The neonate was transfused and is in good health at 3 years of age.

Case 2. A 35-year-old primigravida at 32 weeks and 2 days of gestation was admitted because of decreased fetal movements. Computerized CTG revealed a sinusoidal tracing. Doppler sonography revealed normal fetal measurements, absence of movements, normal amniotic fluid 
volume and umbilical artery waveforms. MCA-PSV was $114 \mathrm{~cm} / \mathrm{s}$ or $2.6 \mathrm{MoM}$ (estimated fetal $\mathrm{Hb} 4.3 \mathrm{~g} / \mathrm{dl}$ ) [29]. An emergency cesarean section was performed and a 2,165-gram male fetus with an Apgar score of 2 and 6 was delivered. Hb was $2.8 \mathrm{~g} / \mathrm{dl}$ and flow cytometry confirmed the presence of a massive FMH. The infant was transfused and was eventually discharged in good condition.

Case 3. A 37-year-old primigravida at 37 weeks and 2 days of gestation was admitted because of decreased fetal movements. CTG upon admission was nonreactive. Ultrasound confirmed absence of fetal movements, but fetal size, amniotic fluid volume and umbilical artery Doppler were normal. MCA-PSV was $103 \mathrm{~cm} / \mathrm{s}$, corresponding to $1.86 \mathrm{MoM}$ (estimated $\mathrm{Hb} 6.3 \mathrm{~g} / \mathrm{dl}$ ) [29]. A 3,000-gram female infant with Apgar scores of 8 and 9 and $\mathrm{Hb}$ of $5.7 \mathrm{~g} /$ $\mathrm{dl}$ was delivered by an emergency cesarean section. Flow cytometry confirmed the presence of severe FMH. The girl was transfused after birth and was eventually discharged in good condition.

\section{Systematic Review}

The systematic research yielded a total of 838 citations. Identification of potentially relevant studies was carried out through abstract scanning and the full text of 628 articles was retrieved. Of these, after removal of duplicates, 16 studies were deemed appropriate to be included in the final review $[8,10,13-26]$. Studies were found suitable for inclusion in the systematic review after critical appraisal according to the published guidelines we used [28]. A flowchart depicting the process from initial literature search to inclusion in the present manuscript is presented in figure 1. The selected articles included case reports, case series, one letter to the editor, one retrospective and one prospective study, and there were no randomized controlled trials. Table 2 shows the characteristics of studies included in this review and a flowchart describing the process of selection of cases included is presented in figure 2. Overall, from the 118 cases collected from 16 articles, 32 pregnant women at $31 \pm 5$ weeks' gestation (range 16-39) were included in this systematic review. Ten of the 32 cases were derived from the only prospective series retrieved from the literature [16]. The maternal age, when available, was $31 \pm 5$ years. Indications for referral were available in 28 cases and included decreased fetal movements (12 cases), maternal trauma (10 cases), fetal hydrops ( 3 cases), and uterine contractions, fetal right atrial enlargement, and twin-twin transfusion syndrome ( 1 case each). The remaining 4 cases were retrieved from a retrospective analysis of intrauterine transfusions. CTG upon admission was described in 24 cases and was

Sonographic Diagnosis of Fetomaternal Hemorrhage
Table 2. Characteristics of studies included in this systematic review

\begin{tabular}{lllll}
\hline $\begin{array}{l}\text { First } \\
\text { author }\end{array}$ & Year & Study design & $\begin{array}{l}\text { Patients, } \\
\mathrm{n}\end{array}$ & $\begin{array}{l}\text { Patients } \\
\text { included, } \mathrm{n}\end{array}$ \\
\hline Baschat & 1998 & case report & 1 & 1 \\
Sueters & 2003 & case reports & 2 & 2 \\
Weisberg & 2004 & case reports & 4 & 3 \\
Wong & 2005 & case report & 1 & 1 \\
Rubod & 2006 & case report & 1 & 1 \\
Malcus & 2006 & case report & 1 & 1 \\
Eichbaum & 2006 & case report & 1 & 1 \\
Votino & 2008 & case report & 1 & 1 \\
Aso & 2009 & case report & 1 & 1 \\
Sikafis & 2010 & case report & 1 & 1 \\
Huissoud & 2010 & letter to the editor & 3 & 2 \\
Siemer & 2010 & case reports & 2 & 2 \\
Friszer & 2010 & case report & 1 & 1 \\
Amann & 2011 & retrospective & 82 & 4 \\
Cosmi & 2012 & prospective & 15 & 10 \\
Singh & 2014 & case report & 1 & 1 \\
\hline
\end{tabular}

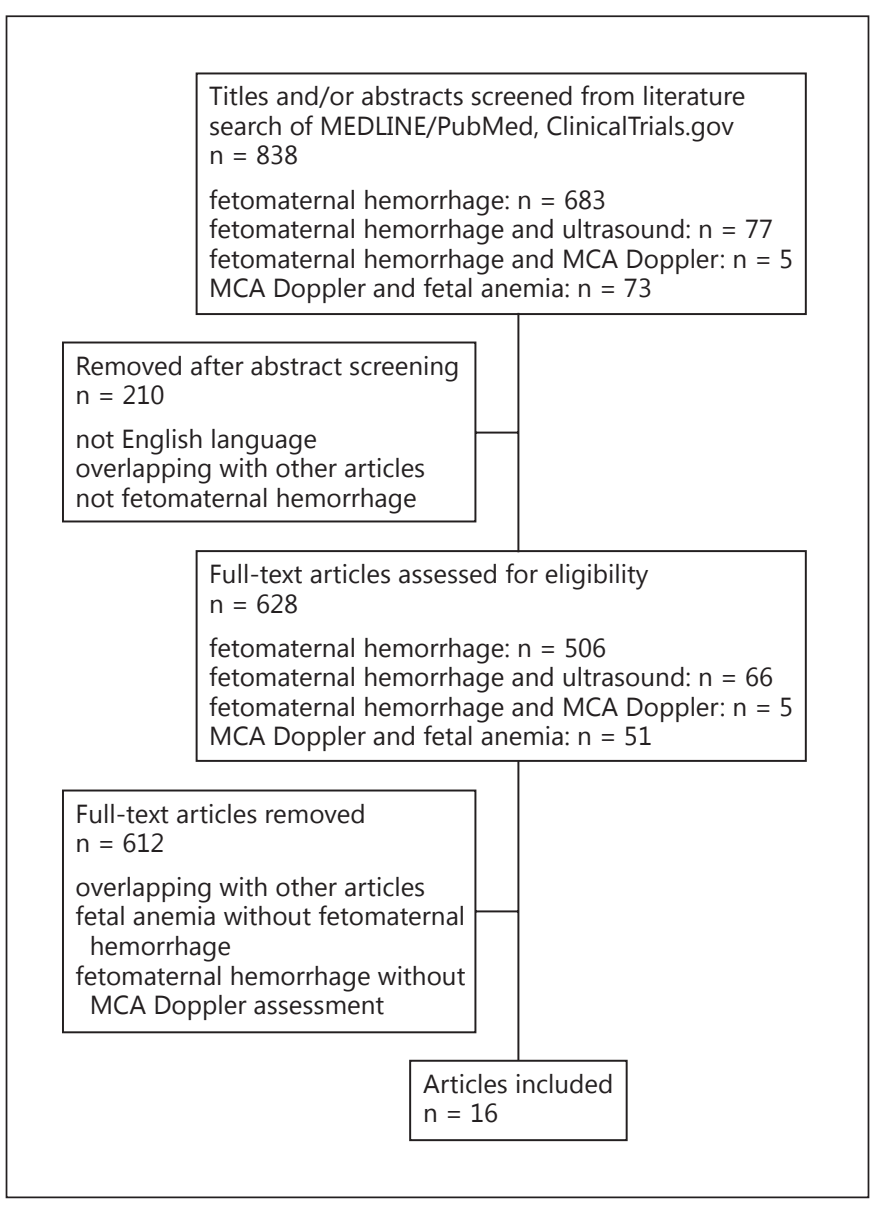

Fig. 1. Flowchart of literature review process. 
categorized as sinusoidal in 17 , nonreactive in 5 , with decelerations and tachycardic in 1 case each. MCA-PSV was $82 \pm 19 \mathrm{~cm} / \mathrm{s}(1.9 \pm 0.3 \mathrm{MoM})$. FMH was confirmed by Kleihauer-Betke test in 27 cases and flow cytometry in 4

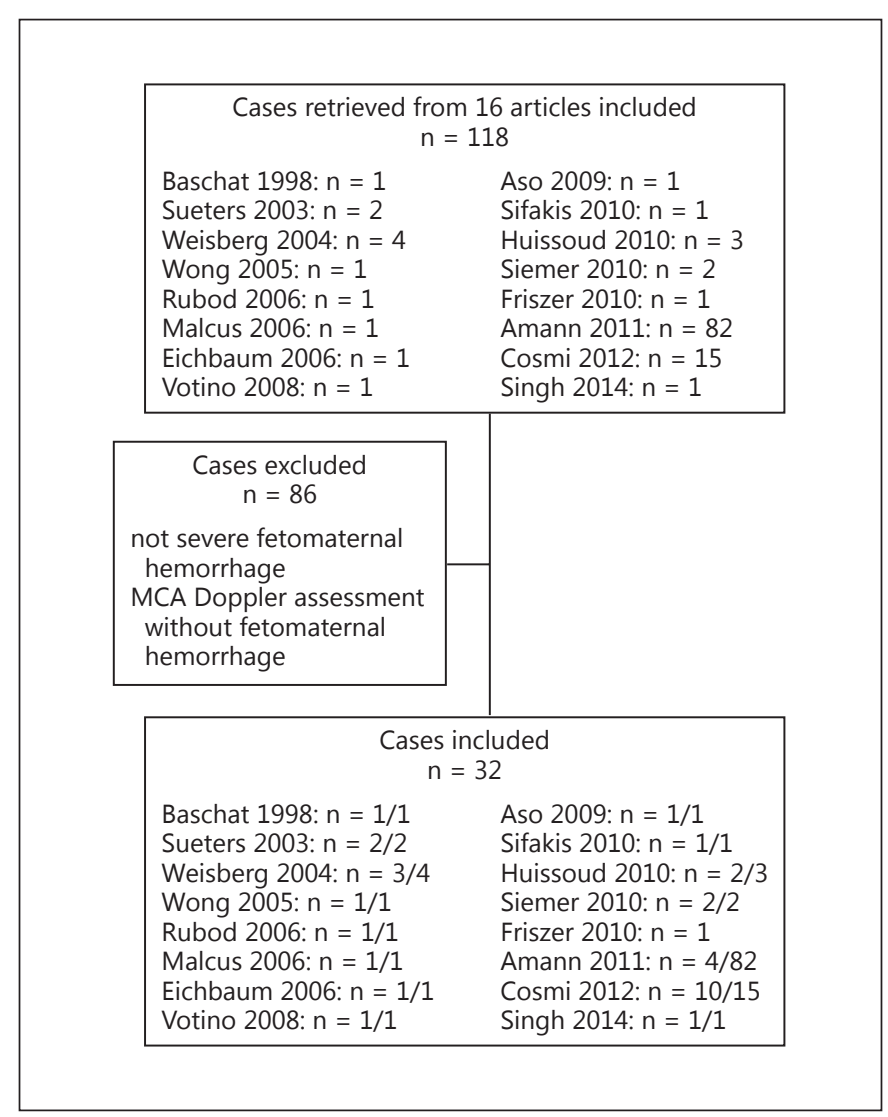

Fig. 2. Flowchart of cases included in this systematic review. and both tests were used in the remaining case. The $\mathrm{Hb}$ value was available in all cases but one [15] and in this case, we retrieved it from the $\mathrm{Ht}$ [30]. Gestational age at delivery was available in 22 cases and it was $32 \pm 4$ weeks. A cesarean section was performed in all cases in which the mode of delivery was described (19/32) [13, 16, 21]. There was one fetal [21] and one neonatal death [14]. Fetuses/ neonates had an initial hemoglobin $(\mathrm{Hb})$ concentration of $4.82 \pm 1.9 \mathrm{~g} / \mathrm{dl}$.

In all cases in which these data were available (20 cases), the fetuses/neonates were transfused only in utero (5 cases) $[2,8,17,21,24,25]$, only after birth (9 cases) [14, $19,20,22,23,25,26]$ or both ( 2 cases) $[10,15]$. In 4 cases, fetuses were transfused but data about postnatal transfusion were not available [13]. In the remaining 12 cases, data about transfusion were not available $[16,18]$.

\section{Combined Series}

Data from all cases included in our analysis (32 cases from the literature review and our own 3 cases) are provided in tables 1 and 3 . The mean gestational age at admission was $31 \pm 5$ weeks. In the available cases, the mean gestational age at delivery was $33 \pm 4$ weeks. CTG was described in 27 cases and was categorized as sinusoidal in 18, nonreactive in 6 , with decelerations in 2 and tachycardic in one. MCA-PSV was $>1.5 \mathrm{MoM}$ in all cases but one and $>2 \mathrm{MoM}$ in 14 cases (see fig. 3 ). The only case with a normal MCA-PSV had a borderline value (1.45 MoM) [19] at 39 weeks. Mean $\mathrm{Hb}$ at fetal blood sampling or at delivery was $4.8 \pm 1.9 \mathrm{~g} / \mathrm{dl}$. There was one fetal demise [21] and one neonatal death [14]. Follow-up information was available in 27 cases and all infants were in good condition.
Fig. 3. MCA-PSV distribution of fetuses included in this study, plotted on the reference range of Mari et al. [27]. Black circles indicate systematic reviews, open squares indicate case series.

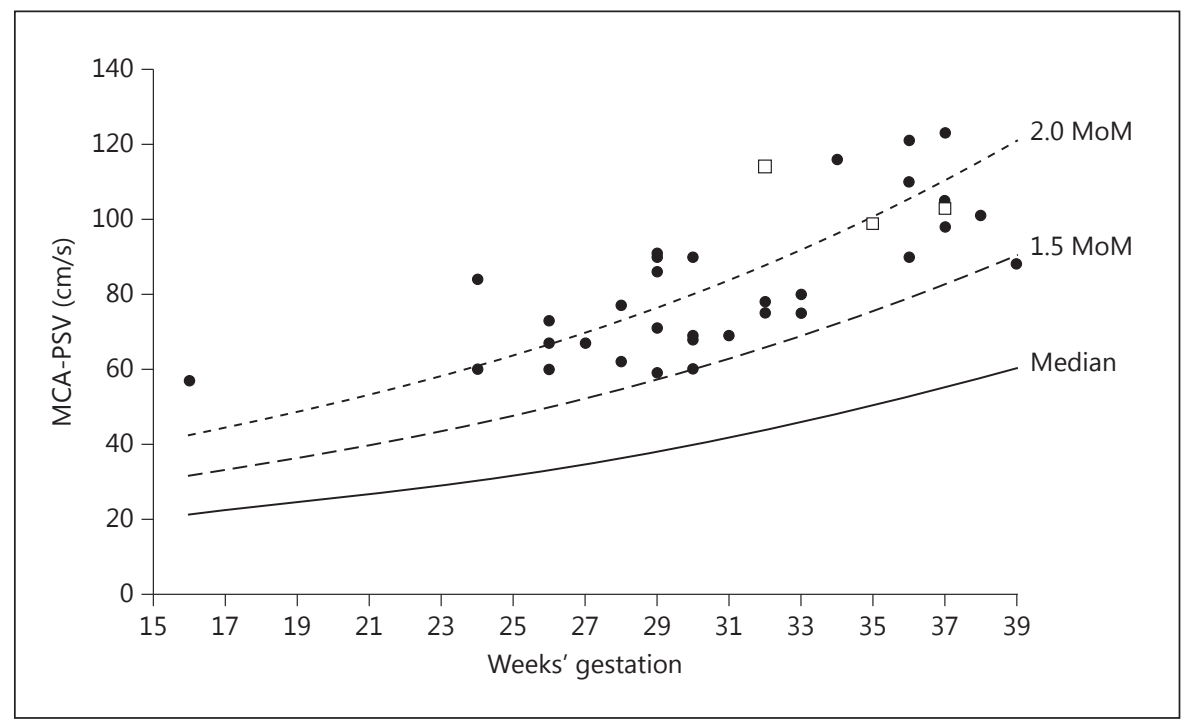




\section{Discussion}

This review of the literature on fetal MCA-PSV obtained in cases of fetal anemia secondary to FMH shows that this Doppler parameter was abnormal in all cases but one that we analyzed. This is not surprising as MCA-PSV is a good indicator of severe fetal anemia independently from the etiology [27, 31-33]. Indeed, all cases in our review but one had an MCA-PSV exceeding 1.5 MoM, the commonly accepted threshold that indicates severe fetal anemia [27], and in 14 of the cases (40\%) the value exceeded 2 MoM. Abnormal CTG was present in all cases but was frequently not specific. A sinusoidal cardiotocogram, which carries the strongest although not exclusive correlation with fetal anemia, was found in $66 \%$ of available cases $(18 / 27)[10,14-16,19,23,25]$. In the remaining, nonreactive tracings, decelerations or tachycardia were found $[8,20,22,24]$. Indeed, the clinical presentation of massive FMH typically includes inconsistent fetal variables: absence of movements, nonreassuring fetal CTG, normal fetal size, normal amount of amniotic fluid, normal umbilical artery Doppler waveforms. Interpretation of such findings is usually a dilemma, and decisionmaking is a major challenge particularly in pregnancies

Table 3. Clinical data of cases from the systematic review of the literature

\begin{tabular}{|c|c|c|c|c|c|c|c|c|c|c|c|c|}
\hline Case & $\begin{array}{l}\text { Indication } \\
\text { for referral }\end{array}$ & GAa & GAd & $\begin{array}{l}\text { CTG } \\
\text { pattern }\end{array}$ & $\begin{array}{l}\text { MCA- } \\
\text { PSV, } \\
\text { MoM }\end{array}$ & $\begin{array}{l}\mathrm{eHb} \\
\mathrm{g} / \mathrm{dl}\end{array}$ & $\begin{array}{l}\mathrm{rHb}, \\
\mathrm{g} / \mathrm{dl}\end{array}$ & $\begin{array}{l}\text { Mode of } \\
\text { delivery }\end{array}$ & $\begin{array}{l}\text { Birth } \\
\text { weight, } g\end{array}$ & IUT & NT & $\begin{array}{l}\text { Clinical } \\
\text { remarks }\end{array}$ \\
\hline Baschat, 1998 & labor & 29 & 29 & sinusoidal & 2.37 & 3.6 & 3.7 & CS & 1,250 & yes & yes & IVH, PVL, RDS \\
\hline Sueters, 2003-1 & DFM & 36 & 36 & sinusoidal & 2.29 & 3.9 & 3.1 & CS & 2,465 & no & yes & none \\
\hline Sueters, 2003-2 & DFM & 30 & 30 & sinusoidal & 2.24 & 3.8 & 1.9 & CS & 1,630 & no & yes & RDS \\
\hline Weisberg, 2004-1 & DFM & 36 & 36 & NA & 2.1 & 4.6 & 2.7 & CS & 2,540 & yes & no & none \\
\hline Weisberg, 2004-2 & DFM & 34 & 34 & sinusoidal & 2.4 & 3.8 & 4.9 & CS & 2,380 & no & yes & pulmonary \\
\hline Wong, 2005 & DFM & 33 & 33 & nonreactive & 1.7 & 6.8 & 3.2 & CS & 2,005 & no & yes & $\begin{array}{l}\text { hypertension } \\
\text { none }\end{array}$ \\
\hline Eichbaum, 2006 & DFM & 32 & 32 & sinusoidal & 1.77 & 6.4 & 4 & CS & 1,860 & yes & yes & none \\
\hline Malcus, 2006 & DFM & 39 & 39 & sinusoidal & 1.45 & 9.6 & 3 & CS & 4,130 & no & yes & NA \\
\hline Rubod, 2006 & DFM & 28 & 28 & decelerations & 2.1 & 4.2 & 2.2 & CS & 3,400 & yes & no & none \\
\hline Votino, 2008 & fetal hydrops & 26 & 33 & nonreactive & 2.19 & 3.8 & 2.9 & CS & 2,075 & yes & no & none \\
\hline Aso, 2009 & DFM & 37 & 37 & sinusoidal & 2.2 & 4.1 & 3.6 & CS & 2,450 & no & yes & neonatal death \\
\hline Sifakis, 2010 & fetal hydrops & 24 & 24 & NA & 2.7 & 5 & 2.5 & NA & NA & yes & 1 & fetal demise \\
\hline Huissoud, 2010-1 & DFM & 29 & 29 & tachycardic & 1.52 & 8.5 & 8.6 & CS & 1,430 & no & NA & NA \\
\hline Huissoud, 2010-2 & maternal trauma & 28 & 28 & NA & 1.6 & 8.2 & 9 & CS & 1,170 & no & NA & NA \\
\hline Siemer, 2010-1 & DFM & 37 & 37 & nonreactive & 1.9 & 5.7 & 3.7 & CS & 3,150 & no & yes & none \\
\hline Siemer, 2010-2 & DFM & 37 & 37 & nonreactive & 1.77 & 6.7 & 5 & CS & 3,020 & no & yes & none \\
\hline Friszer, 2010 & fetal hydrops & 29 & 32 & NA & 1.8 & 5.7 & 4.5 & CS & 1,530 & yes & No & none \\
\hline Amann, 2011-1 & NA & 29 & 29 & NA & 2.2 & 3.8 & 3.3 & NA & NA & yes & NA & NA \\
\hline Amann, 2011-2 & NA & 29 & 29 & NA & 2.3 & 3.6 & 3.1 & NA & NA & yes & NA & NA \\
\hline Amann, 2011-3 & NA & 16 & 34 & NA & 2.7 & 4 & 7.7 & NA & NA & yes & NA & NA \\
\hline Amann, 2011-4 & NA & 30 & 30 & NA & 1.5 & 8.6 & 6.5 & CS & NA & yes & NA & NA \\
\hline Cosmi, 2012-1 & TTTS & 26 & NA & sinusoidal & 1.8 & 5.9 & 6 & CS & NA & no & NA & RDS, BPD \\
\hline Cosmi, 2012-2 & maternal trauma & 24 & NA & sinusoidal & 1.9 & 4.6 & 4.7 & NA & NA & no & NA & RDS, NEC \\
\hline Cosmi, 2012-3 & maternal trauma & 26 & NA & sinusoidal & 2 & 4.5 & 5 & NA & NA & no & NA & RDS, BPD \\
\hline Cosmi, 2012-4 & maternal trauma & 27 & NA & sinusoidal & 1.9 & 5.1 & 5.1 & NA & NA & no & NA & RDS \\
\hline Cosmi, 2012-5 & maternal trauma & 30 & NA & sinusoidal & 1.7 & 6.9 & 6.5 & NA & NA & no & NA & RDS \\
\hline Cosmi, 2012-6 & maternal trauma & 30 & NA & sinusoidal & 1.7 & 6.7 & 6.2 & NA & NA & no & NA & RDS \\
\hline Cosmi, 2012-7 & maternal trauma & 31 & NA & sinusoidal & 1.6 & 7.4 & 6.9 & NA & NA & no & NA & RDS \\
\hline Cosmi, 2012-8 & maternal trauma & 32 & NA & sinusoidal & 1.7 & 7 & 6.7 & NA & NA & no & NA & RDS \\
\hline Cosmi, 2012-9 & maternal trauma & 33 & NA & sinusoidal & 1.6 & 7.7 & 7.2 & NA & NA & no & NA & RDS \\
\hline Cosmi, 2012-10 & maternal trauma & 36 & NA & sinusoidal & 1.7 & 7.2 & 7.1 & NA & NA & no & NA & RDS \\
\hline Singh, 2014 & fetal cardiopathy & 38 & 38 & nonreactive & 1.82 & 6.3 & 4 & $\mathrm{CS}$ & NA & no & yes & NA \\
\hline
\end{tabular}

$\mathrm{GAa}=$ Gestational age at admission; GAd = gestational age at delivery; eHb = estimated $\mathrm{Hb}$ value; $\mathrm{rHb}=$ real $\mathrm{Hb}$ value (at delivery or at fetal blood sampling); IUT = intrauterine transfusion; NT = neonatal transfusion; DFM = decreased fetal movements; TTTS = twin-to-twin transfusion syndrome; $\mathrm{CS}$ = cesarean section; $\mathrm{IVH}=$ intraventricular hemorrhage; $\mathrm{PVL}=$ periventricular leukomalacia; $\mathrm{RDS}=$ respiratory distress syndrome; $\mathrm{BPD}=$ bronchopulmonary dysplasia; NEC = necrotizing enterocolitis; NA = not available. 
remote from term. In our own case series and in the review of the published literature, MCA-PSV was by far the most effective predictor of severe FMH.

We do acknowledge that our review has a major weakness in that it depends largely upon case reports that certainly favor the inclusion of cases with positive Doppler findings. Indeed, both the sensitivity and positive predictive value of MCA-PSV in our review approach $100 \%$, which is probably unrealistic. The available data do not allow estimating the accuracy, particularly the specificity, of MCA-PSV assessment in the diagnosis of severe FMH. Only a large prospective study would allow appropriate calculations, but given the low prevalence of severe FMH, an enormous number of patients need to be examined. Experience with fetal erythroblastosis suggests that MCAPSV has a high sensitivity in the prediction of fetal anemia, but a relatively low positive predictive value [34]. We suggest, however, that an increased MCA-PSV, which can be obtained and interpreted rapidly, could at least indicate the need for a maternal blood test to diagnose FMH, such as a Kleihauer-Betke or flow cytometry.
In most countries, pregnant patients are recommended to report rapidly decreased perception of fetal movements, because this is associated with an increased risk of adverse outcome [35-38]. However, there is not a general consensus on which test to perform in these cases. Usually, the first approach is CTG and ultrasound evaluation of fetal size, movements and amniotic fluid volume [39]. A similar diagnostic workup is recommended after maternal trauma [40]. Severe FMH may occur in both circumstances and we therefore suggest that in such cases it would be reasonable to obtain MCA-PSV. This may rapidly provide a major clue to the diagnosis of an otherwise elusive obstetric complication that is potentially fatal and yet can be treated easily and effectively.

\section{Disclosure Statement}

The authors deny conflicts of interest in connection with this article.

\section{References}

1 Akanli LF, Cohen-Addad NE, Malabanan NV, Margono F, Krilov MA: Massive fetomaternal hemorrhage. Am J Perinatol 1997;14: 271-273.

2 de Almeida V, Bowman JM: Massive fetomaternal hemorrhage: Manitoba experience. Obstet Gynecol 1994;83:323-328.

3 Kosasa TS, Ebesugawa I, Nakayama RT, Hale RW: Massive fetomaternal hemorrhage preceded by decreased fetal movement and a nonreactive fetal heart rate pattern. Obstet Gynecol 1993;82(suppl):711-714.

4 Zizka Z, Calda P, Zlatohlavkova B, Haakova L, Cerna M, Jirasek JE, et al: Massive fetomaternal transplacental hemorrhage as a perinatology problem, role of $\mathrm{ABO}$ fetomaternal compatibility - case studies. Med Sci Monit 2001;7:308-311.

5 Laube DW, Schauberger CW: Fetomaternal bleeding as a cause for 'unexplained' fetal death. Obstet Gynecol 1982;60:649-651.

6 Stroustrup A, Plafkin C, Savitz DA: Impact of physician awareness on diagnosis of fetomaternal hemorrhage. Neonatology 2014;105: 250-255.

7 Maier JT, Schalinski E, Schneider W, Gottschalk U, Hellmeyer L: Fetomaternal hemorrhage $(\mathrm{FMH})$, an update: review of literature and an illustrative case. Arch Gynecol Obstet 2015;292:595-602.
8 Rubod C, Houfflin V, Belot F, Ardiet E, Dufour P, Subtil D, et al: Successful in utero treatment of chronic and massive fetomaternal hemorrhage with fetal hydrops. Fetal Diagn Ther 2006;21:410-413.

9 Bovicelli L, Ghi T, Pilu G, Farina A, Savelli L, Simonazzi G, et al: Prenatal diagnosis of a complete mole coexisting with a dichorionic twin pregnancy: case report. Hum Reprod 2004;19:1231-1234.

10 Eichbaum M, Gast AS, Sohn C: Doppler sonography of the fetal middle cerebral artery in the management of massive fetomaternal hemorrhage. Fetal Diagn Ther 2006;21:334338.

11 Samadi R, Greenspoon JS, Gviazda I, Settlage RH, Goodwin TM: Massive fetomaternal hemorrhage and fetal death: are they predictable? J Perinatol 1999;19:227-229.

12 Markham LA, Charsha DS, Perelmuter B: Case report of massive fetomaternal hemorrhage and a guideline for acute neonatal management. Adv Neonatal Care 2006;6:197-205; quiz 206-207.

13 Amann C, Geipel A, Muller A, Heep A, Ritgen J, Stressig R, et al: Fetal anemia of unknown cause - a diagnostic challenge. Ultraschall Med 2011;32(suppl 2):E134-E140.

14 Aso K, Tsukimori K, Yumoto Y, Hojo S, Fukushima K, Koga T, et al: Prenatal findings in a case of massive fetomaternal hemorrhage associated with intraplacental choriocarcinoma. Fetal Diagn Ther 2009;25:158-162.
15 Baschat AA, Harman CR, Alger LS, Weiner CP: Fetal coronary and cerebral blood flow in acute fetomaternal hemorrhage. Ultrasound Obstet Gynecol 1998;12:128-131.

16 Cosmi E, Rampon M, Saccardi C, Zanardo V, Litta P: Middle cerebral artery peak systolic velocity in the diagnosis of fetomaternal hemorrhage. Int J Gynaecol Obstet 2012;117:128130 .

17 Friszer S, Cortey A, Pierre F, Carbonne B: Using middle cerebral artery peak systolic velocity to time in utero transfusions in fetomaternal hemorrhage. Obstet Gynecol 2010;115: 1036-1038.

18 Huissoud C, Fraser W, Rudigoz RC, Audibert F: Middle cerebral artery Doppler in fetomaternal hemorrhage. J Matern Fetal Neonatal Med 2010;23:573-575.

19 Malcus P, Bjorklund LJ, Lilja M, Teleman P, Laurini R: Massive feto-maternal hemorrhage: diagnosis by cardiotocography, Doppler ultrasonography and ST waveform analysis of fetal electrocardiography. Fetal Diagn Ther 2006;21:8-12.

20 Siemer J, Wendler A, Schild RL, Grab D: Massive fetomaternal hemorrhage and severe anemia in the newborn - two case reports. Ultraschall Med 2010;31:192-194.

21 Sifakis S, Koukoura O, Konstantinidou AE, Kikidi K, Prezerakou M, Kaminopetros P: Sonographic findings in severe fetomaternal transfusion. Arch Gynecol Obstet 2010;281: 241-245. 
22 Singh P, Swanson T: Acute and chronic fetal anemia as a result of fetomaternal hemorrhage. Case Rep Obstet Gynecol 2011;2014: 296463.

23 Sueters M, Arabin B, Oepkes D: Doppler sonography for predicting fetal anemia caused by massive fetomaternal hemorrhage. Ultrasound Obstet Gynecol 2003;22:186-189.

24 Votino C, Mirlesse V, Gourand L, Parnet-Mathieu F, Bessieres B, Daffos F: Successful treatment of a severe second trimester fetomaternal hemorrhage by repeated fetal intravascular transfusions. Fetal Diagn Ther 2008;24: 503-505.

25 Weisberg L, Kingdom J, Keating S, Ryan G, Seaward G, Kelly E, et al: Treatment options in fetomaternal hemorrhage: four case studies. J Obstet Gynaecol Can 2004;26:893-898.

26 Wong G, Levine D: Increased systolic peak velocity in fetal middle cerebral artery blood flow shown by Doppler sonography in acute fetomaternal hemorrhage. J Ultrasound Med $2005 ; 24: 243-246$

27 Mari G, Deter RL, Carpenter RL, Rahman F, Zimmerman R, Moise KJ Jr, et al: Noninvasive diagnosis by Doppler ultrasonography of fetal anemia due to maternal red-cell alloimmunization. Collaborative Group for Doppler Assessment of the Blood Velocity in Anemic Fetuses. N Engl J Med 2000;342:9-14.
28 Stroup DF, Berlin JA, Morton SC, Olkin I, Williamson GD, Rennie D, et al: Meta-analysis of observational studies in epidemiology: a proposal for reporting. Meta-analysis Of Observational Studies in Epidemiology (MOOSE) group. JAMA 2000;283:20082012.

29 Mari G, Detti L, Oz U, Zimmerman R, Duerig P, Stefos T: Accurate prediction of fetal hemoglobin by Doppler ultrasonography. Obstet Gynecol 2002;99:589-593.

30 Nutritional anaemias. Report of a WHO scientific group. World Health Organ Tech Rep Ser 1968;405:5-37.

31 Moise KJ Jr: The usefulness of middle cerebral artery Doppler assessment in the treatment of the fetus at risk for anemia. Am J Obstet Gynecol 2008; 198:161.e1-e4.

32 Delle Chiaie L, Buck G, Grab D, Terinde R: Prediction of fetal anemia with Doppler measurement of the middle cerebral artery peak systolic velocity in pregnancies complicated by maternal blood group alloimmunization or parvovirus B19 infection. Ultrasound Obstet Gynecol 2001;18:232-236.
33 Baschat AA, Oepkes D: Twin anemia-polycythemia sequence in monochorionic twins: implications for diagnosis and treatment. Am J Perinatol 2014;31(suppl 1):S25-S30.

34 Bullock R, Martin WL, Coomarasamy A, Kilby MD: Prediction of fetal anemia in pregnancies with red-cell alloimmunization: comparison of middle cerebral artery peak systolic velocity and amniotic fluid OD450. Ultrasound Obstet Gynecol 2005;25:331-334.

35 Practice bulletin No. 145: antepartum fetal surveillance. Obstet Gynecol 2014;124:182192.

36 Heazell AE, Froen JF: Methods of fetal movement counting and the detection of fetal compromise. J Obstet Gynaecol 2008;28:147-154

37 Reddy A, Moulden M, Redman CW: Antepartum high-frequency fetal heart rate sinusoidal rhythm: computerized detection and fetal anemia. Am J Obstet Gynecol 2009;200: 407.e1-e6.

38 Reduced Fetal Movements. Green-top Guideline No. 57. Royal College of Obstetricians and Gynaecologists.

39 Liston R, Sawchuck D, Young D: Fetal health surveillance: antepartum and intrapartum consensus guideline. J Obstet Gynaecol Can 2007;29(suppl 4):S3-S56.

40 Brown HL: Trauma in pregnancy. Obstet Gynecol 2009;114:147-160 